\title{
La coeducación en los libros de texto de Educación Primaria. Análisis de las desigualdades en los textos, las imágenes y las temáticas ${ }^{1}$
}

Coeducation in Primary Education textbooks. Analysis of inequalities in texts, images and themes.

\author{
Santiago Sevilla-Vallejo \\ Departamento de Lengua española \\ Universidad de Salamanca \\ santiagosevilla@usal.es
}

\section{Resumen}

El presente trabajo indaga si los materiales didácticos utilizados por el profesorado, concretamente los libros de texto, promueven la igualdad con la incorporación de la perspectiva de género en sus contenidos. Para ello, se ha realizado un estudio de dos libros de texto de Lengua Castellana y Literatura del curso 2019- 2020. El análisis muestra un abuso del masculino, con su uso a través de ejemplos gramaticales, en la selección de autores o en la frecuencia de aparición en las imágenes de varones frente a mujeres. Del mismo modo, no parece reconocerse la contribución de las mujeres a la cultura, la ciencia o el progreso y las imágenes analizadas no reflejarían la diversidad social de la actualidad. En cuanto a la temática, se ha detectado que no se ha producido una incorporación de la perspectiva de género en los materiales estudiados.

Palabras claves: Coeducación, Perspectiva de género, Identidad de género, Igualdad de oportunidades, Lenguaje inclusivo, Libros de texto.

\begin{abstract}
This study investigates whether the teaching materials used by teachers, specifically textbooks, promote equality by incorporating the gender perspective in their content. For this, a study of two textbooks of Spanish Language and Literature for the 2019-2020 academic year has been carried out. The analysis shows an abuse of the masculine form,
\end{abstract}

${ }^{1}$ Recibido: 08/01/2021 Evaluado: 14/02/21 Aceptado: 19/03/2021 
with its use through grammatical examples, in the selection of authors or in the frequency of appearance in the images of men versus women. Similarly, the contribution of women to culture, science or progress does not seem to be recognized and the images analyzed would not reflect the social diversity of today. Regarding the theme, it has been detected that there has not been an incorporation of the gender perspective in the materials studied.

Keywords: Coeducation, Gender perspective, Gender identity, Equal opportunities, Inclusive language, Textbooks.

\section{Fundamentos}

La coeducación en el Sistema Educativo ha hecho grandes avances en las últimas décadas, gracias a la aprobación de legislaciones con el objetivo de promover la igualdad entre hombres y mujeres. Sin embargo, no se puede hablar de coeducación si se producen desequilibrios en las aulas. Este trabajo se centra en uno de los elementos del proceso de la enseñanza-aprendizaje, los recursos pedagógicos, concretamente los libros de texto, que deben favorecer el respeto a las diferencias de género, facilitando la igualdad de oportunidades. Sin embargo, se presentan dos problemas. En primer lugar, los desequilibrios no resultan fáciles de detectar porque, tras la ley 3/2007, las editoriales eliminaron los comentarios vejatorios o discriminatorios para la mujer, pero se mantuvo la discriminación oculta, que supone el silenciamiento de la figura femenina, un ocultamiento de los logros alcanzados y un desequilibrio sutil de la realidad social. En segundo lugar, las editoriales no han llevado a cabo una incorporación de la perspectiva de género en sus libros de texto. La carencia de esta perspectiva en los manuales didácticos se explica por ciertas deficiencias que presenta la normativa, ya que la legislación vigente regula y controla la producción de materiales didácticos, pero no la supervisa.

El diccionario jurídico español del Poder Judicial define la coeducación como: “Acción educativa que potencia la igualdad real de oportunidades y la eliminación de cualquier tipo de discriminación por razón de orientación sexual, identidad de género o expresión de género". Según Moreno (1987), "Coeducar no es yuxtaponer en una misma clase a individuos de ambos sexos, ni tampoco es unificar, eliminando las diferencias mediante la presentación de un modelo único. No es uniformizar las mentes de niñas y niños sino que, por el contrario, es enseñar a respetar lo diferente y a disfrutar de la riqueza que ofrece la variedad". Asimismo, Lucini (1998) señala que: "se entiende por coeducación el proceso educativo que favorece el desarrollo integral de las personas con independencia del sexo al que pertenezcan". Por lo tanto, para poder hablar de escuela coeducativa, deberían corregirse los desequilibrios y desigualdades entre el alumnado. Esta temática surgió con el fin de la escuela segregada y su currículum diferenciado, que no produjo una integración curricular porque se presentó a las niñas contenidos que previamente ya se habían definido para los niños. De acuerdo con esta idea, Subirats y Brullet (1988) afirman que esta falta de integración de ambos sistemas convierte a la escuela mixta en perpetuadora de la transmisión de géneros tradicionales. La transmisión de conocimientos, tradiciones, valores e ideas que se hacen en la escuela es sesgada, obedeciendo a los estereotipos que ya existían. 
La visibilización del rol femenino tiene una larga tradición investigadora recogido en: Moreno (1987); Subirats y Brullet (1988); Blanco (2000); Lomas (2009a); Carranza (2009); Tomé (2009); Vega (2009); Blanch y Obiols (2012). Asimismo, ha sido estudiado cómo es necesario educar al alumnado con un espíritu crítico contra el sexismo y la discriminación sexual (Lomas, 2009b). La construcción de la identidad sociocultural se basa en un conocimiento compartido del mundo. Sin embargo, Lomas apunta que, si este conocimiento es sesgado, no se estará más que perpetuando ideologías, estilos de vida y estereotipos. En este sentido, los libros de texto tienen una gran trascendencia porque reflejan "una visión de la realidad que corresponde a modelos sociales hegemónicos: una visión patriarcal, androcéntrica, en la que los hombres continúan siendo el referente que se pretende generalizar como universal" (Consejería de Educación de Andalucía, 2007). Resulta desconcertante que, pese a la conciencia de su importancia y la abundancia de estudios sobre la importancia del "currículum oculto" de los libros de texto: Moreno (1987); Fernández (1989); Torres (1991); Molina (1994); López y Fernández (1999); Vázquez y Manasero (1999); Flecha (2005), el cambio en este sentido haya sido superficial. Hace casi treinta años, Subirats (1993) ya señaló que hay que valorar las actitudes, roles y otras formas de caracterización psicológica de los géneros para una educación igualitaria.

\section{Objetivo}

Valorar las posibles discriminaciones de género e intereseccionales en dos libros de texto utilizados en la actualidad en las aulas de Primaria, tanto en su lenguaje, en sus imágenes y en las temáticas que trabajan.

\section{Metodología}

El presente trabajo realiza un análisis cuantitativo en dos libros de texto de las principales editoriales vigentes en la Comunidad de Madrid en el curso 2019-2020:

Tabla 1. Editoriales

\begin{tabular}{|l|c|c|c|c|c|}
\hline ISBN del libro & Asignatura & Proyecto & Curso & $\begin{array}{c}\text { Año de } \\
\text { publicación }\end{array}$ & Editorial \\
\hline $978-$ & $\begin{array}{c}\text { Lengua } \\
\text { Castellana y } \\
\text { Literatura }\end{array}$ & Savia & $5^{\circ}$ & 2014 & $\begin{array}{c}\text { Grupo SM } \\
\text { Educación }\end{array}$ \\
\hline $978-$ \\
8468048895 & $\begin{array}{c}\text { Lengua } \\
\text { Castellana y } \\
\text { Literatura } \\
\text { contigo }\end{array}$ & $\begin{array}{c}\text { Saber hacer } \\
\text { co }\end{array}$ & 2019 & $\begin{array}{c}\text { Santillana } \\
\text { Educación, } \\
\text { S.L. }\end{array}$ \\
\hline
\end{tabular}

Fuente: elaboración propia. 
Se aplica la escala elaborada por Fresnillo (2020) a partir de los trabajos de Subirats (1993), Blanco (2000), Torres (2009), y Lomas (2009a, 2009b), y las guías de buenas prácticas de diferentes organismos y administraciones (ver Anexo). La escala se ha dividido principalmente en tres categorías de análisis (texto, imagen y temática). A partir de las frecuencias arrojadas por el análisis se comparan estos resultados transformados en porcentajes.

\section{Análisis de los resultados}

\section{Resultados de la Editorial SM}

a. Análisis de textos

\section{Gráfico 1}

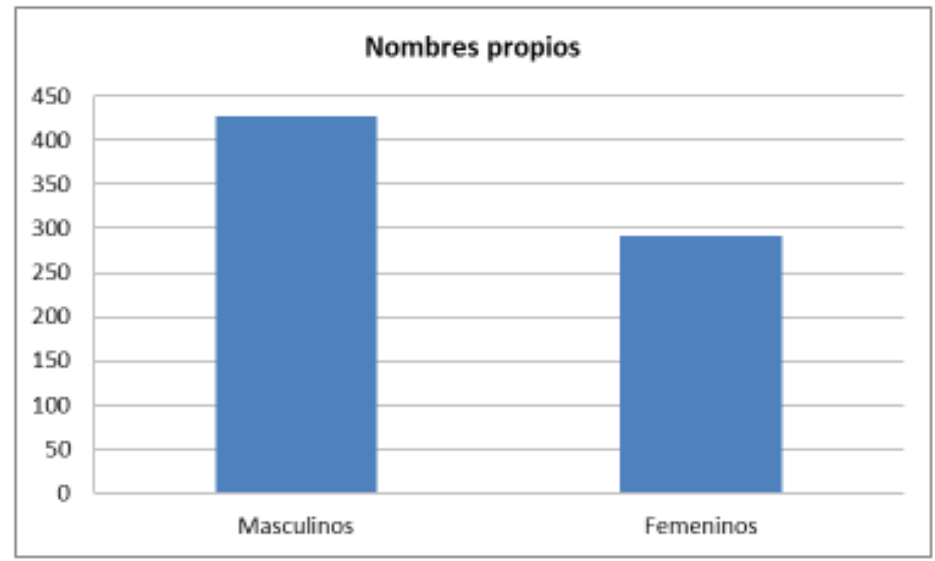

Fuente: elaboración propia

\section{Gráfico 2}

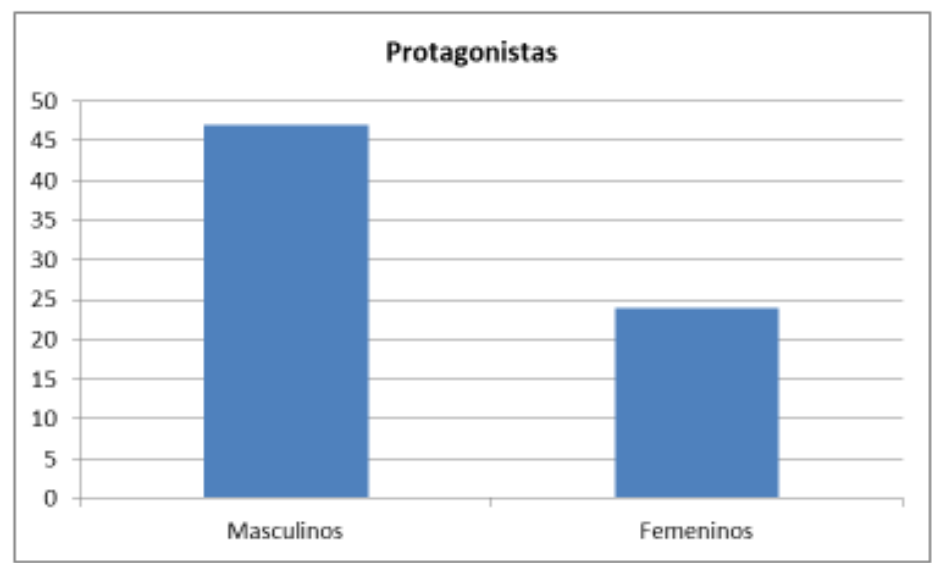

Fuente: elaboración propia

El análisis de los textos de la editorial deja patente un predominio masculino frente al femenino, tal y como puede apreciarse en el gráfico con los resultados. 
En las páginas del manual hay pocas referencias explícitas a contextos tales como la casa o el trabajo. En muchos casos se trata de frases simples y concretas, sin apenas referencias para una posible contextualización, lo que dificulta la enmarcación en un ámbito concreto. No obstante, se ha llevado a cabo un análisis de las profesiones que se relacionan con cada uno de los géneros. Si bien estas no están estereotipadas, lo que sí se recoge es un mayor número de profesiones afines con lo masculino, tales como jardinero, alcalde, escritor, albañil, locutor, granjero, entre otras. En contraposición con las relacionadas con lo femenino, aparecen ejemplos tales como jueza, costurera, vendedora, geóloga, entrenadora o basurera. Este mayor número de profesiones vinculadas con figuras masculinas aumenta las posibilidades de identificación de los niños con una mayor diversidad laboral. Los resultados se recogen en este gráfico.

\section{Gráfico 3}

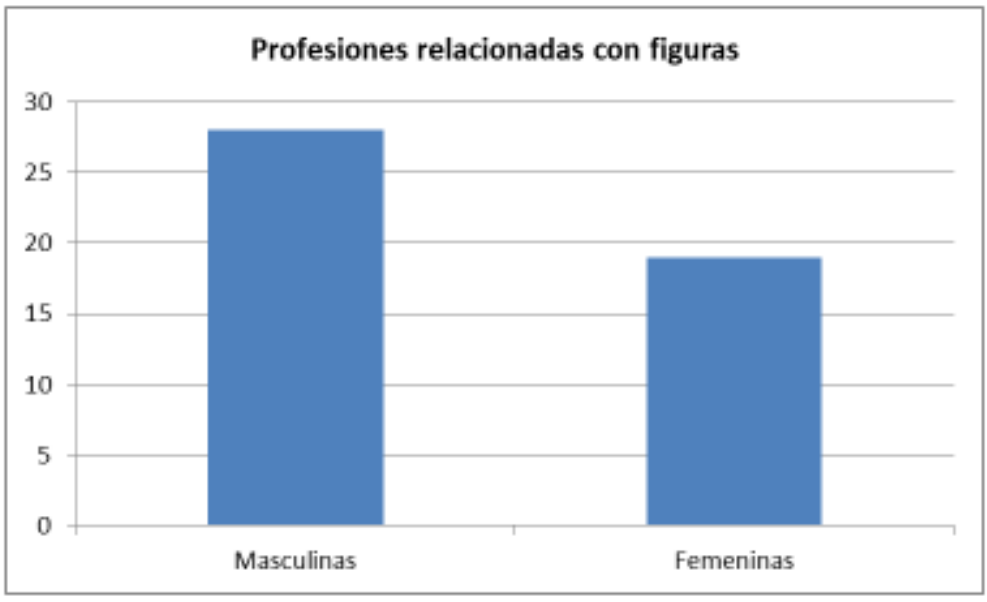

Fuente: elaboración propia

En relación con las referencias a la Ciencia en las páginas de SM, son muy pocas a nivel de texto. Siendo en un 89,47 por ciento referentes masculinos, lo que dificulta la visibilidad del papel femenino y podría conllevar a una menor identificación de las niñas con modelos femeninos en estos ámbitos. Algunos de los referentes masculinos, tanto en el ámbito de la Ciencia como de la Historia, son Arquímedes, Franklin, Gutemberg, Amudsen, Magallanes o Marco Antonio, frente a Cleopatra VIII o Catalina de Medici, como los dos únicos ejemplos femeninos citados. 
Gráfico 4

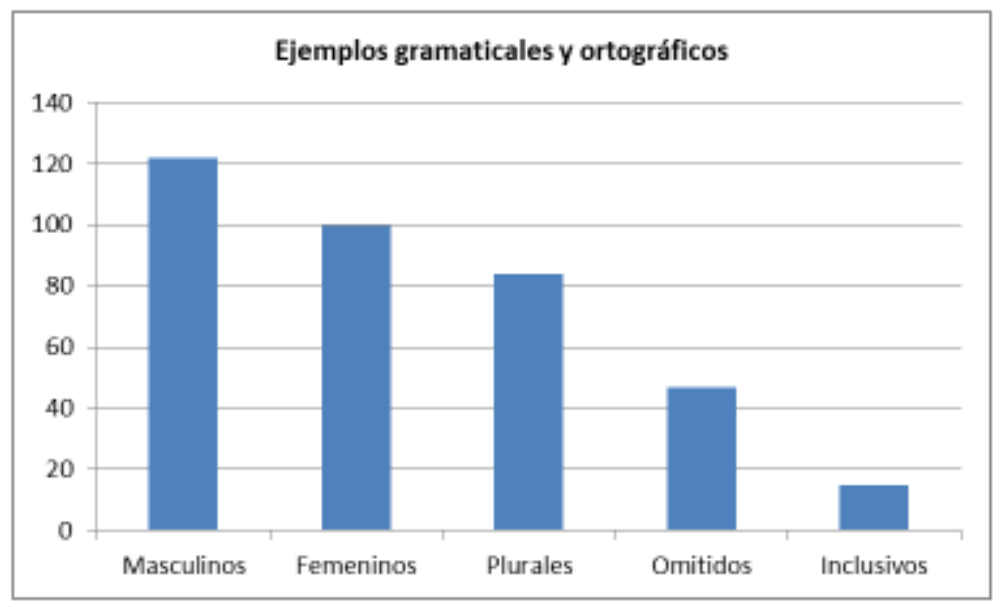

Fuente: elaboración propia

Con respecto a los ejemplos gramaticales y ortográficos, puede apreciarse un intento por parte de la editorial de incluir términos genéricos inclusivos tales como "patrulla", "el público", "la audiencia", "gente", "personas" o "la evolución humana". En esta misma línea, la editorial se ha servido de términos y fórmulas que evitan la posible asignación a un masculino o femenino, tales como "Antes de hacer el viaje, debes vacunarte para no enfermar" (p. 261). El análisis de las secciones de comprensión lectora y de los dictados aportan los datos sobre la posible identificación de la autoría de los textos. Como puede observarse, hay un predominio de autores masculinos. Cabe destacar, el elevado porcentaje de textos en los que no es posible realizar una identificación de su fuente. La siguiente tabla refleja los resultados obtenidos.

\section{Gráfico 5}

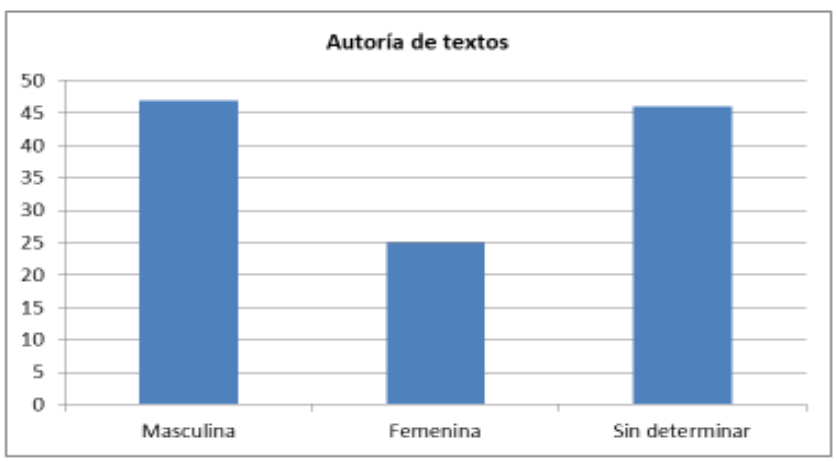

Fuente: elaboración propia

En el nivel de análisis de textos, SM utiliza la fórmula de segunda persona del singular, tales como "Realiza un análisis completo de los siguientes sustantivos" (p. 35) o "Lee estos 
carteles y elige la lista de las cuatro opciones verdaderas" (p. 87). Con esta fórmula se implica al alumnado siendo protagonista de su proceso de aprendizaje. Además, la editorial también recoge otras fórmulas en los enunciados que implican la integración de los estudiantes. Otro ejemplo sería: "En grupos, pensad qué es importante saber..." (p. 88). Sin embargo, se incluyen algunos enunciados, con un uso del plural masculino que hacen referencia y visibilizan solo a dicho género en el aula, como por ejemplo "Añadid en cada diapositiva o cartulina imágenes atractivas, para que vuestros compañeros os voten" (p. 139) o "Exponed a vuestros compañeros la información que habéis tenido en el cuestionario" (p. 89).

\section{b. Análisis de imágenes}

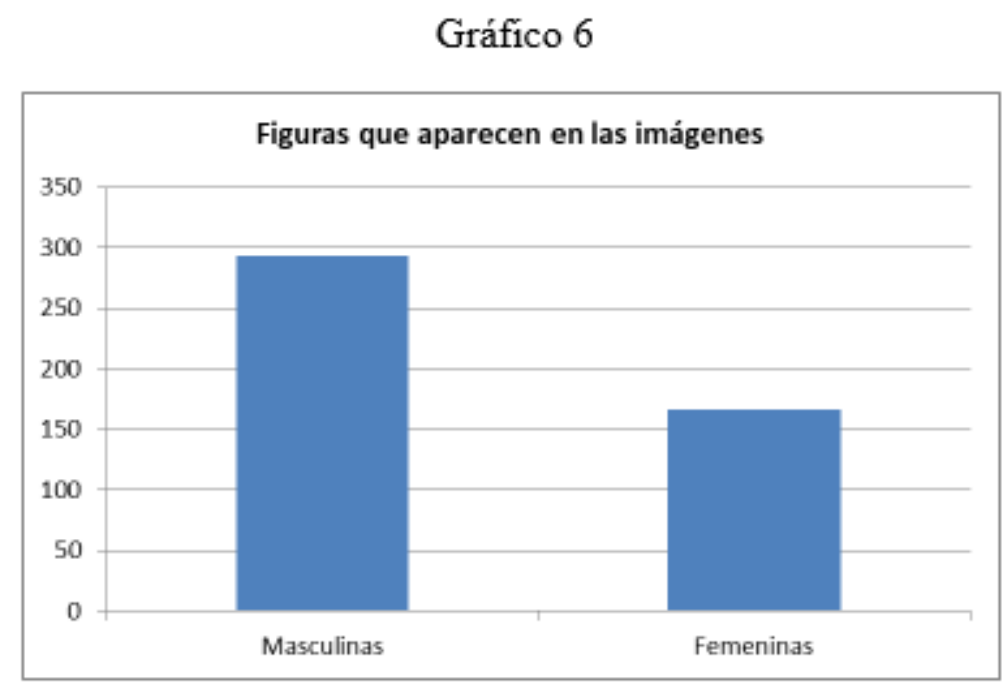

Fuente: elaboración propia

Es destacable un predominio de la figura masculina frente a la femenina. Además, analizando las diferentes edades del ser humano, las imágenes de bebés o edad anciana son muy poco frecuentes, mientras que la iconografía de las personas adultas es más habitual en SM, seguidas de las imágenes referentes a la infancia. Con lo cual los modelos de identificación estarían principalmente en estas edades. 


\section{Gráfico 7}

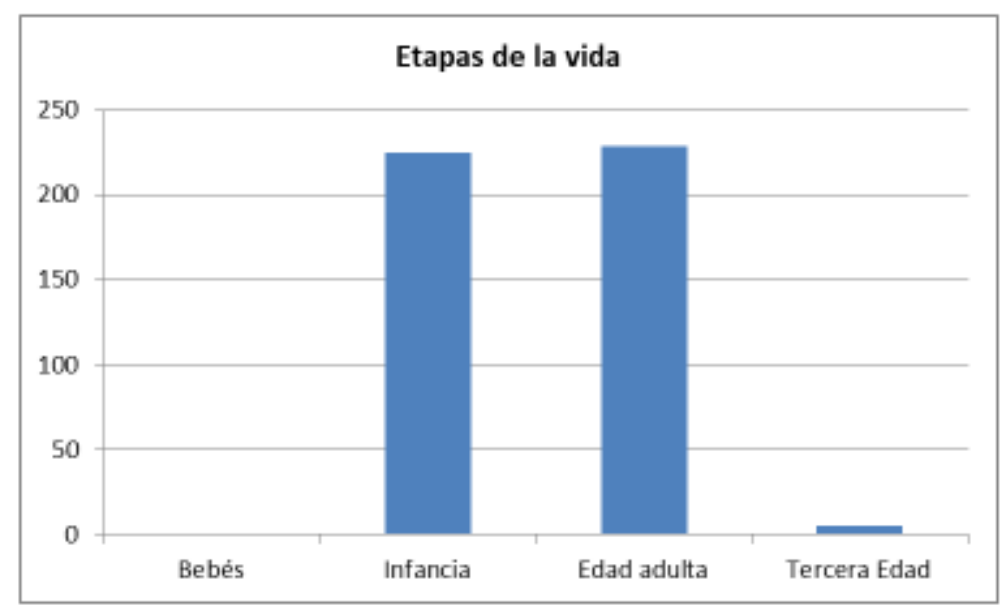

Fuente: elaboración propia

La editorial ha preferido no utilizar imágenes relacionadas con la casa, las labores domésticas o ámbitos laborales. Algunas escenas son difíciles de catalogar como lugares de trabajo por la ambigüedad que plantean, como, por ejemplo, personas tocando en una banda de música. En este caso, no se puede saber si se tratan de músicos profesionales o si por el contrario son aficionados que lo hacen en su tiempo libre. Entre las representaciones pictóricas relacionadas con el ocio destacan los parques, el patio del colegio, bibliotecas y la playa, entre otras. En las pocas imágenes relacionadas con labores del hogar, las figuras masculinas las que realizan este tipo de tareas.

\section{Imágenes 1-2}
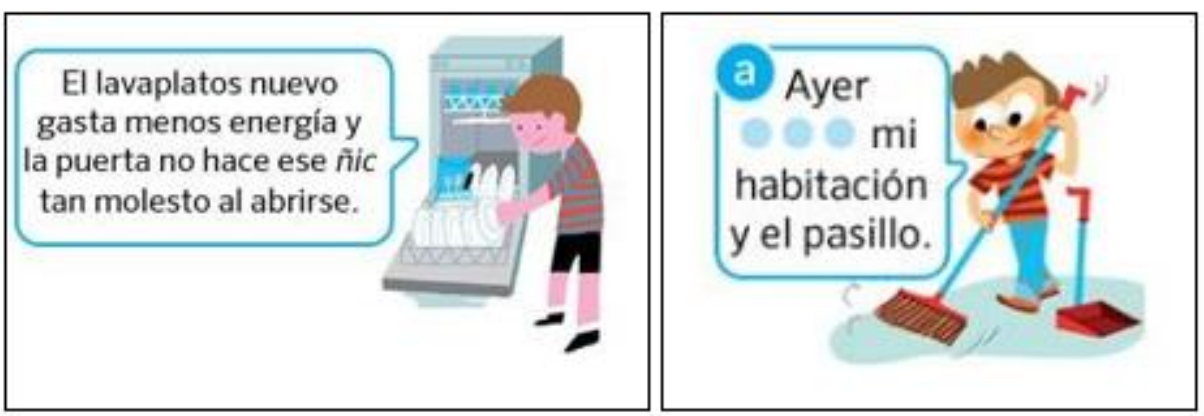

Fuente: Editorial SM 
Con respecto a la vinculación de las imágenes con la Ciencia y la Tecnología, se constata que existe un predominio de la figura masculina en este entorno, aunque, como se puede ver a continuación, se pueden encontrar ejemplos de ambos géneros.

Imágenes 3-6
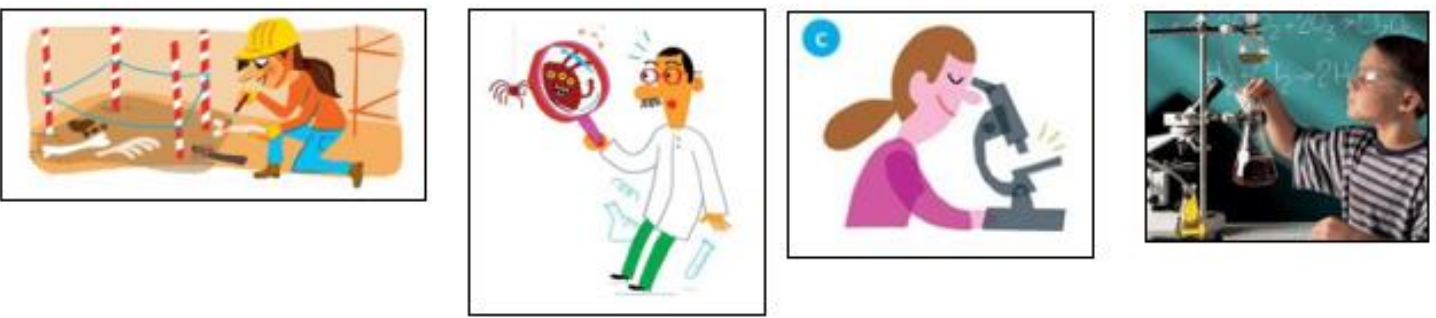

Fuente: Editorial SM

En el análisis, aparecen muy pocas imágenes que reflejen la diversidad. Las que sí la muestran están relacionadas con diferentes capacidades físicas como la ceguera o la sordera, pero ninguna de ellas refleja diferentes capacidades psíquicas.

\section{Imágenes 7-8}

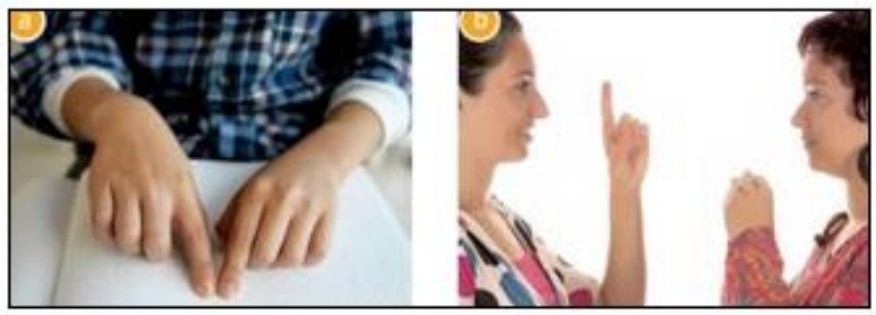

Fuente: Editorial SM

\section{c. Análisis de las temáticas}

Se recoge un uso habitual de los contenidos clásicos de los libros de texto: consumo y reciclado, viajes y aventuras o amistad. Sin embargo, no se han encontrado temáticas que posibiliten la prevención de la violencia de género o la corresponsabilidad de obligaciones familiares o domésticas. No se fomenta el análisis de los medios de comunicación donde hay sexismo, como por ejemplo en los anuncios publicitarios. El estudio muestra, además, que no se recogen las aportaciones de las mujeres a las Ciencias, las Artes, la Tecnología y las Letras. Se ha encontrado un ejemplo de intento de visibilización de las mujeres localizado en la unidad 9 "Hace millones de años..." donde se recogen diferentes periodos de la prehistoria. En la lectura principal se encuentran oraciones del tipo "Físicamente, los neandertales se 
parecen a los hombres actuales" (p. 199), "Estos hombres, ya sedentarios construyeron casas permanentes con arcilla y vigas de madera". Pero, en el último párrafo puede leerse:

Con frecuencia se olvida el papel de las mujeres en estas etapas culturales, pero a ellas les debemos con toda probabilidad el origen de la agricultura. Mientras que los hombres iban a cazar, las mujeres se encargaban de recolectar granos y frutas, así como de capturar pequeños animales, es decir, la alimentación básica. Es posible que las mujeres también se dieran cuenta también de que los granos recolectados podían volver a sembrarse. Para ello, seleccionaban los granos de mayor tamaño (p. 201).

La unidad 1 "Juntos en el colegio" marca como objetivo la convivencia y la aceptación de la diversidad. Sin embargo, no se profundiza en ese contenido. Se trabaja un fragmento de Matilda de Roald Dahl, sobre el que se organiza esta unidad didáctica. En este caso, la diversidad se trata a través de un personaje de ficción, pero no hay mención de ninguna pluralidad real y no hay un trabajo específico sobre la aceptación de la diferencia, sino que se representa a través de una niña con poderes que es distinta a los demás, pero no se trabaja en las diferencias sociales, culturales, físicas o psicológicas, religiosas o de género.

\section{Resultados de la Editorial Santillana}

\section{a. Análisis de textos}

Esta tabla recoge los principales resultados obtenidos del análisis de los textos del manual de Lengua castellana y Literatura de la editorial.

\section{Gráfico 8}

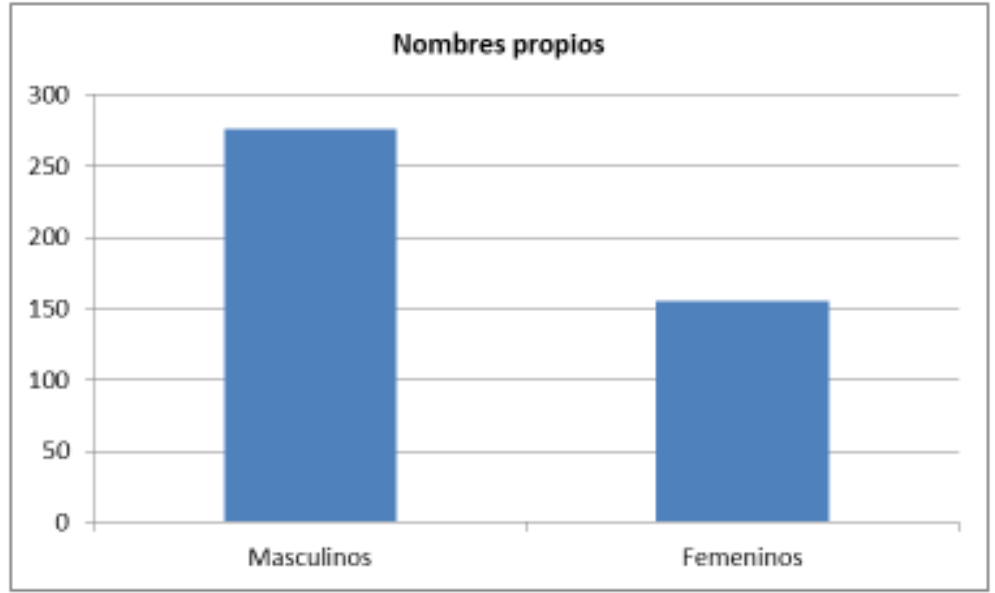

Fuente: elaboración propia

Los nombres masculinos predominan sobre los femeninos, diferencia observada también en la relación de personajes. El estilo de las oraciones es simple y no presenta grandes referentes, 
por lo que hace difícil contextualizar en un ambiente doméstico, en un entorno laboral o de ocio. Se han analizado las profesiones que se relacionan con todas las personas que se recogen en los contenidos. Las figuras masculinas están relacionadas con cincuenta y seis diferentes profesiones no estereotipadas -escritor, director de orquesta, jefe de estudios, pescador, albañil, nadador.... Mientras que, las figuras femeninas se relacionan con diez profesiones -enfermera, granjera, maestra, alcaldesa... Dadas estas cifras, las posibilidades de identificación de las chicas con diferentes profesiones son menores.

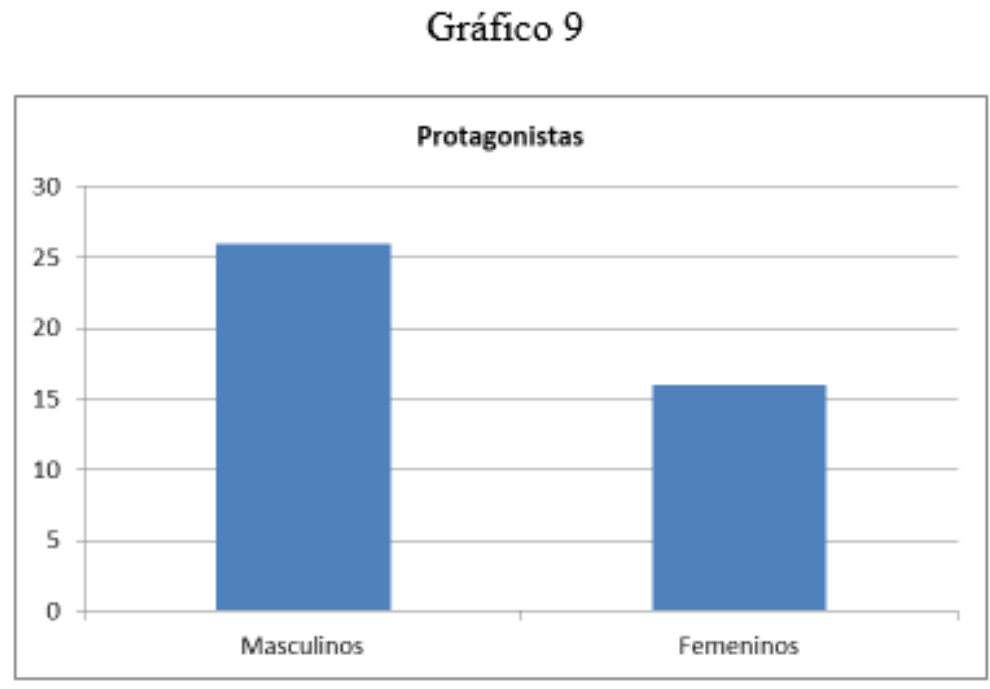

Fuente: elaboración propia

En relación con el ámbito científico y tecnológico, las referencias en el libro no son abundantes, siendo todos los casos referentes masculinos. El manual de Santillana recoge algunos como Pedro Duque o Neil Armstrong. Con respecto a referentes en otros ámbitos, todos ellos son de género masculino -Cristóbal Colón, Dalí, Amudsen o Félix María de Samaniego- frente a un único referente femenino, Marina Alabau, deportista olímpica. El resultado del análisis de los ejemplos y ejercicios de gramática y de ortografía, ha aportado diversos datos. Por un lado, se aprecia el esfuerzo por parte de Santillana de utilizar ejemplos gramaticales que eviten la identificación con alguno de los dos sexos. La editorial utiliza elude el sujeto, como por ejemplo "Me prestó su raqueta y balón” (p. 73), "Sus pisadas están en la casa" (p. 73). Además, en los modelos gramaticales se encuentran términos que incluyen a ambos géneros, tal y como "Un cuarteto de cuerda amenizaba la velada" (p. 71) y "La plantilla de la fábrica es reducida" (p. 55). Santillana también emplea el uso de las fórmulas plurales, como se observa en "Unos niños jugaban al parchís en un rincón” (p. 57) o "Ellos representaron con mímica títulos de libros y películas" (p. 59). De entre todas las categorías de ejemplos gramaticales, el uso del masculino es el más numeroso. En cuanto al masculino: "Jaime es menos travieso que su hermana" (p. 103) y "César estudió Medicina, pero no ejerce como médico" (p. 55). Los casos de ejercicios a través del femenino constituyen el 19,96 por ciento del total, como se muestra en "Marta se empadronó en esa ciudad" (p. 145) o "Claudia leyó un libro de aventuras” (p. 177). 


\section{Imagen 9}

Las palabras que indican el pais, la región, la localidad... de donde procede una persona se llaman gentilicios. As; la palabra griego es un gentlicio.

Los gentilicios se foman ariadiendo sufios a los nombres de paises, regiones, localidades... Estos son algunos de los sutios más usados para formar gentilicios:

- -eno, ena: brasileño "- tes, -esa: portugués " ti irani

"- enser nicaragciense "-ano, -ana: fallano " tho, tha: tunecino

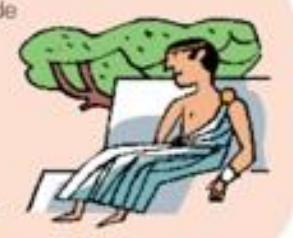

Fuente: Editorial SM

Imagen 10

\section{Oraciones copulativas y predicativas}

Seguin el verbo, las oraciones pueden ser copulativas y predicativas.

- Oraciones copulativas. Son las que contienen los verbos ser. estar o parecer. Por ejemplo: Lucia es muy graciosa.

- Oraciones predicativas. Son aqualas en las que el núcleo del predicado es un verbo distinto de ser, estar o parecer. Los verbos de las craciones predicativas suelen expresar acciones o procesos. Por ejemplo: Áwaro ha metido una canasta.

Fuente: Editorial SM

\section{Gráfico 10}

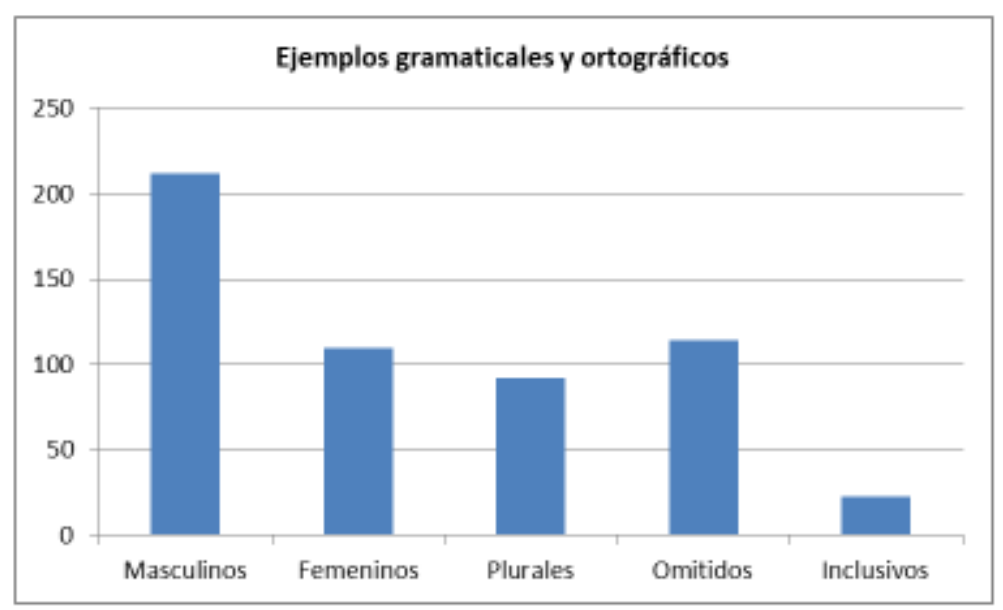

Fuente: elaboración propia

En la primera categoría de análisis también se evaluó la autoría de los textos que aparecen en el manual de Lengua. Para su estudio se utilizaron tanto los contenidos de las comprensiones 
lectoras como los dictados, aunque ninguno de estos recoge el nombre de la fuente. En aquellas lecturas donde sí queda constancia de la persona autora del texto, puede apreciarse una frecuencia más elevada en el número de autores masculinos que femeninas. Este elevado número de lecturas a las que no se les puede atribuir la autoría supone una pérdida de visibilización de sus creadores.

\section{Gráfico 11}

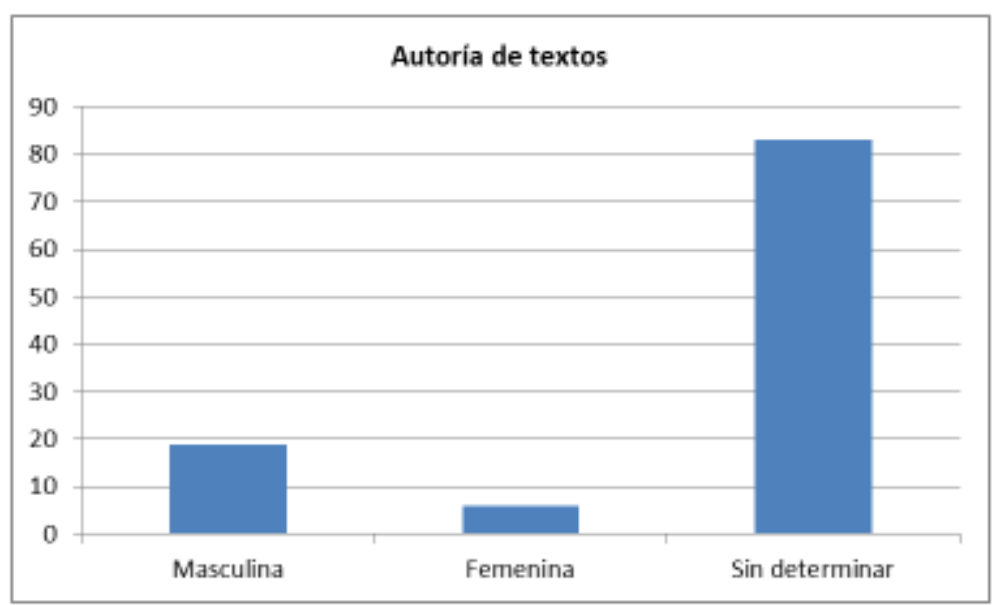

Fuente: elaboración propia

Al igual que con la editorial SM, se ha llevado a cabo un estudio de los enunciados de las tareas que aparecen en el libro de Santillana. Esta editorial recoge algunas formas en las que hay un abuso del masculino, como por ejemplo "Con ayuda de un adulto, busca en Internet..." o "Representa con uno de tus compañeros...", como si la actividad estuviera dirigida solo a niños: "Formad grupos de siete niños". Esta preferencia por la forma masculina no visibiliza a las niñas del aula.

\section{b. Análisis de las imágenes}

A nivel de imagen, el análisis revela una predominancia masculina, con una representación de 61,77 por ciento frente a las figuras femeninas. 


\section{Gráfico 12}

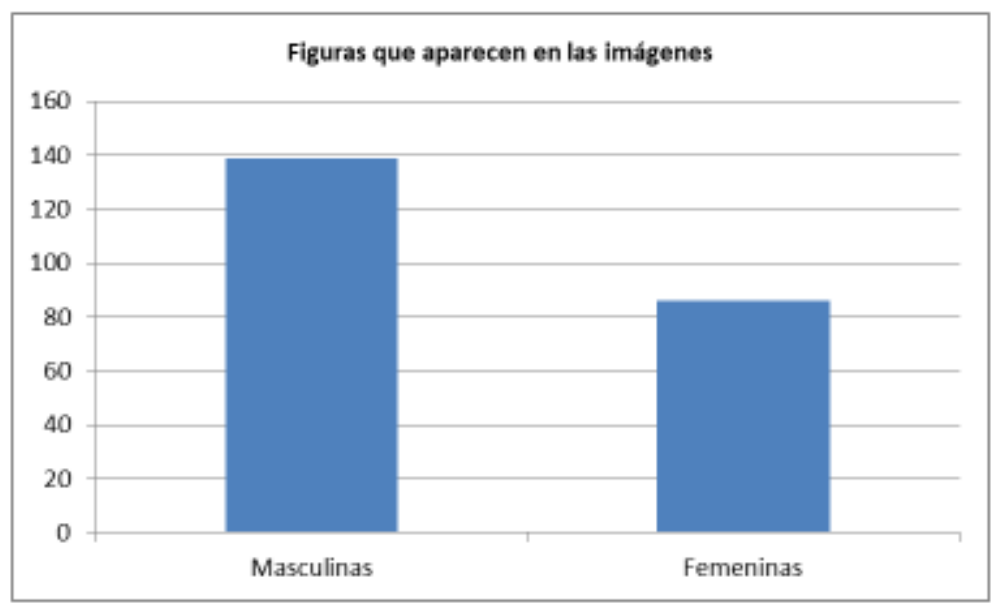

Fuente: elaboración propia

El estudio de la siguiente gráfica pone de manifiesto que Santillana no refleja diversidad en las páginas de sus libros. Por un lado, sólo se encuentra una imagen vinculada a diferentes capacidades físicas, en este caso es una imagen de lectura de un texto en braille. Y por otro, las imágenes de bebés o de la tercera edad son prácticamente nulas. El grueso de las imágenes representa o bien población adulta o infantil. Si bien es cierto que, apenas hay diferencias entre la frecuencia de niñas y niños, sí hay disparidad en la edad adulta donde el 76,19 por ciento son representaciones masculinas.

\section{Gráfico 13}

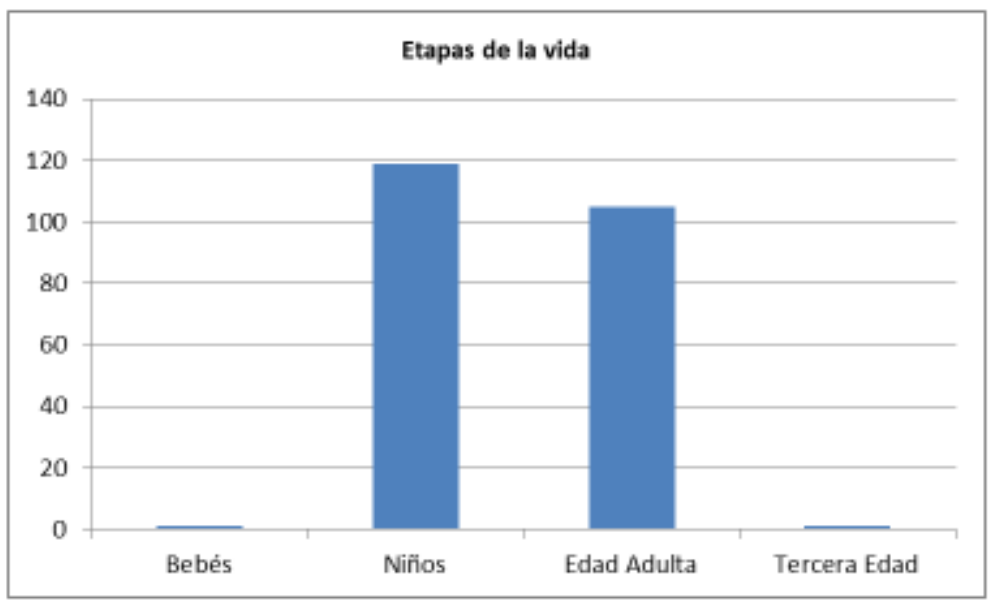

Fuente: elaboración propia

La editorial evita utilizar imágenes que permitan una contextualización clara. No es habitual encontrar en las páginas del manual escenas relacionadas con el trabajo o la casa. Es más, no aparecen representaciones de personas realizando tareas domésticas. Son frecuentes las figuras de animales o de objetos. Las imágenes relacionadas con los niños son, en la mayoría 
de los casos, en entornos escolares como el colegio, la biblioteca o el patio. Con respecto a su vinculación con la Ciencia, se pueden encontrar muy pocas ilustraciones que se relacionen con figuras humanas, siendo las que aparecen, mayoritariamente masculinas.

\section{Imágenes 11-14}
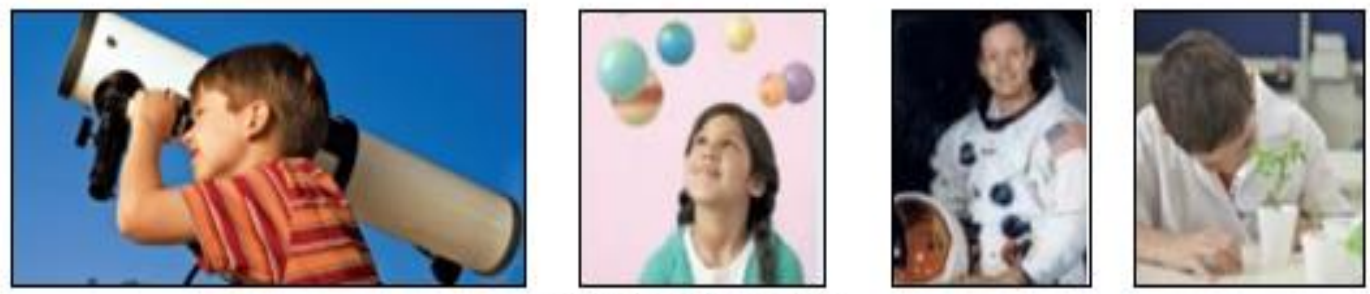

Fuente: Editorial SM

\section{c. Análisis de las temáticas}

El manual de Lengua castellana y Literatura de Santillana está articulado en base a quince unidades didácticas. Cada unidad recoge una temática diferente, tales como viajes, animales, sentimientos, tradiciones o medios de comunicación. No se abordan de manera directa ninguna materia sobre corresponsabilidades en la sociedad actual. Algunos de los temas plantean debates, pero estas actividades están orientadas al protagonismo masculino. Asimismo, aparecen algunas reflexiones tales como "¿Qué crees que ocurriría si el hombre nunca hubiera inventado la pólvora?" o "Durante siglos se pensó que el hombre no llegaría nunca a la Luna...". No se observa la intención de incluir a la figura femenina en los logros de la Humanidad, ni convertirla en referente de los diferentes momentos históricos.

\section{Conclusiones}

En este trabajo, se ha observado que, si bien los estudios de género reclaman una educación verdaderamente igualitaria, todavía está muy presente un curriculum oculto en los libros de texto. Se ha apuntado como causa la falta de una normativa operativa al respecto. En las dos editoriales analizadas, sigue dándose un predominio de la figura masculina en los dos primeros ámbitos estudiados: texto e imagen. En el último ámbito del estudio, la temática, tras la realización del análisis, podría afirmarse que no se ha realizado una incorporación de la perspectiva de género en ninguna de las dos editoriales en las que se ha basado el estudio. Por lo tanto, podría indicarse que los libros de texto siguen mostrando un desequilibro de géneros en sus contenidos. Si bien se trata de una muestra pequeña, la consistencia del análisis es ilustrativa. Asimismo, se ha aportado una herramienta para llevar a cabo el análisis del grado de igualdad de género e interseccional de los libros de texto.

\section{Agradecimiento}

Se agradece a Sandra Fresnillo del Saz la colaboración realizada en su Trabajo de Fin de Grado en la Universidad de Alcalá, en el que se basa este estudio. 


\section{Referencias}

Blanch, J. P., y Obiols, E. S. (2012). Las mujeres en la enseñanza de la Historia: ¿hasta cuándo serán invisibles? Cadernos de Pesquisa do CDHIS, 25(1), pp. 91-117.

Blanco García, N. (2000). El sexismo en los materiales educativos de la E.S.O. Sevilla: Instituto Andaluz de la Mujer.

Carranza, M.E. (2009). Mujer y antropología. En Mujer y educación: Educar para la igualdad, educar desde la diferencia, pp. 21-31. Barcelona: Grao.

Fernández Enguita, M. (1989). La tierra prometida: La contribución de la escuela a la igualdad de la mujer. Revista de educación, 290, pp. 21-41.

Flecha, C. (2005). La categoría" género" en los estudios feministas. En Miradas desde la perspectiva de género: estudios de las mujeres, pp. 33-48. Madrid: Narcea.

Fresnillo del Saz, S. (2020). Análisis de libros de texto de lengua castellana y literatura desde una perspectiva coeducativa. TFG. Universidad de Alcalá.

Lomas C. (2009a). El aprendizaje de las entidades femeninas y masculinas en la cultura de masas. En Mujer y educación: Educar para la igualdad, educar desde la diferencia, pp. 95-110. Barcelona: Grao.

Lomas C. (2009b). El sexismo en los libros de texto. En Mujer y educación: Educar para la igualdad, educar desde la diferencia, pp. 193-207. Barcelona: Grao.

Lucini, F. (1998). Temas transversales y Educación en valores. Madrid: Anaya.

Molina Plaza, S. (1994). Estado actual de la igualdad de oportunidades para ambos sexos en textos de inglés. Encuentro: revista de investigación e innovación en la clase de idiomas, 7, pp. 78-87.

Moreno, A. (1987). El arquetipo viril protagonista de la Historia: ejercicios de lectura no androcéntrica. Barcelona: La Sal.

Subirats, M. (1993). El sexismo en los libros de texto: análisis y propuesta de un sistema de indicadores. Ministerio de Asuntos Sociales. Madrid: Instituto de la Mujer.

Subirats, M. y Brullet, C. (1988). Rosa y azul. Las Transmisión de los Géneros en la Escuela Mixta. Madrid: Instituto de la Mujer. 
Tomé A. (2009). Luces y sombras en el camino hacia una escuela coeducativa. En Mujer y educación: Educar para la igualdad, educar desde la diferencia, pp. 169-182. Barcelona: Grao.

Torres, J. (1991). El curriculum oculto. Madrid: Ediciones Morata.

VVAA (2007). Cambios Sociales y Género. Guía didáctica. Sevilla: Consejería de Educación de la Junta de Andalucía

Vázquez A., y Manasero, M.A. (1999). Características del conocimiento científico: creencias de los estudiantes. Enseñanza de las ciencias: revista de investigación y experiencias didácticas, 17(3), pp. 377-395.

Vega C. (2009). La mujer en la historia y la historia de las mujeres. En Mujer y educación: Educar para la igualdad, educar desde la diferencia, pp. 13-19. Barcelona: Grao. 


\section{Anexo}

C1: Número de veces que en los textos se nombra o se presenta lo siguiente.

\begin{tabular}{|l|l|l|}
\hline & MUJERES & HOMBRES \\
\hline SC11 Nombres propios & & \\
\hline SC12 Personajes protagonistas & & \\
\hline SC13 Realizan un trabajo remunerado? & & \\
\hline $\begin{array}{l}\text { SC14 Realizan labores domésticas o de } \\
\text { cuidados }\end{array}$ & & \\
\hline $\begin{array}{l}\text { SC15 Aparecen en ámbitos relacionados } \\
\text { con la Ciencia, la Técnica, las Nuevas } \\
\text { Tecnologías }\end{array}$ & & \\
\hline $\begin{array}{l}\text { SC16 Aparecen realizando labores } \\
\text { relacionadas con el ocio (deporte, cine, } \\
\text { lectura, viajes...) }\end{array}$ & & \\
\hline & $\begin{array}{l}\text { SI (No DE } \\
\text { VECES) }\end{array}$ & NO (NDE VECES) \\
\hline $\begin{array}{l}\text { SC17 Uso de términos masculinos } \\
\text { en los ejemplos gramaticales }\end{array}$ & & \\
\hline $\begin{array}{l}\text { SC18 Uso de términos } \\
\text { femeninos en los ejemplos } \\
\text { gramaticales }\end{array}$ & & \\
\hline
\end{tabular}

\begin{tabular}{|l|l|l|}
\hline SC19 Términos genéricos & & \\
\hline $\begin{array}{l}\text { SC110 Masculinos } \\
\text { genéricos }\end{array}$ & & \\
\hline $\begin{array}{l}\text { SC111Términos que no permiten identificar } \\
\text { la persona }\end{array}$ & & \\
\hline $\begin{array}{l}\text { SC112 Se identifica la autoria de las } \\
\text { fuentes que aparecen con } \\
\text { nombres y apellidos masculinos }\end{array}$ & \\
\hline $\begin{array}{l}\text { SC113 Se identifica la autoría de las fuentes } \\
\text { que aparecen con nombres y apellidos } \\
\text { femeninos }\end{array}$ & & \\
\hline $\begin{array}{l}\text { SC113 No se identifica la autoria de las } \\
\text { fuentes que aparecen con nombres y apellidos }\end{array}$ & & \\
\hline OBSERVACIONES: & & \\
& & \\
\hline
\end{tabular}




\section{Imágenes}

C2: Las imágenes

\begin{tabular}{|l|l|l|}
\hline & MUJERES & HOMBRES \\
\hline $\begin{array}{l}\text { SC21 Aparecen (independientemente de la } \\
\text { edad) }\end{array}$ & & \\
\hline SC22 Bebés & & \\
\hline SC23 Niñez & & \\
\hline SC24 Edad adulta & & \\
\hline SC25 Personas mayores & & \\
\hline SC26 Aparecen en la casa & & \\
\hline $\begin{array}{l}\text { SC27 Aparecen realizando un trabajo } \\
\text { remunerado }\end{array}$ & & \\
\hline $\begin{array}{l}\text { SC28 Realizan labores domésticas o de } \\
\text { cuidado }\end{array}$ & & \\
\hline $\begin{array}{l}\text { SC29 En lugares de ocio } \\
\text { SC210 Destaca por sus capacidades fisicas o } \\
\text { intelectuales }\end{array}$ & & \\
\hline $\begin{array}{l}\text { SC211 En posesión y uso de la ciencia y } \\
\text { tecnología }\end{array}$ & & \\
\hline OBSERVACIONES: & & \\
\hline
\end{tabular}

C3: Las temáticas que se tratan en los libros de texto y el enfoque con que se abordan

\begin{tabular}{|l|l|l|}
\hline & $\begin{array}{l}\text { SI (N DE } \\
\text { VECES) }\end{array}$ & NO (N DE VECES) \\
\hline $\begin{array}{l}\text { SC31 Reflejan la presencia y las aportaciones } \\
\text { que los hombres han realizado a la } \\
\text { Humanidad }\end{array}$ & & \\
\hline $\begin{array}{l}\text { SC32 Reflejan la presencia y las aportaciones } \\
\text { que las mujeres han realizado a la } \\
\text { Humanidad }\end{array}$ & & \\
\hline $\begin{array}{l}\text { SC33 Hombres y niños realizan tareas } \\
\text { domésticas y cuidan a personas mayores? }\end{array}$ & & \\
\hline $\begin{array}{l}\text { SC34 Ofrecen información para entender el } \\
\text { silenciamiento del papel de la mujer en } \\
\text { algunos ámbitos y momentos de la }\end{array}$ & & \\
Historia? & & \\
\hline OBSERVACIONES: & & \\
\hline
\end{tabular}

